\title{
An approach for optimising railway traffic flow on high speed lines with differing signalling systems
}

\author{
N. Zhao, C. Roberts \& S. Hillmansen \\ Birmingham Centre for Railway Research and Education, \\ University of Birmingham, $U K$
}

\begin{abstract}
Signalling systems are critical in ensuring the safe movement of trains within a network. The choice of signalling system employed on a particular line has a direct impact on the journey time and hence the capacity of the line. Computer simulations provide a viable method for evaluating and analysing the performance of signalling systems.

This paper describes the development of a multi-train simulator in which five different signalling systems are simulated on a common section of high-speed line operating with two trains. The simulator is used to compare train performance, including differences in journey time and train energy consumption.

The result shows that, by using more advanced signalling systems and optimal train control strategies, interactions between trains can be avoided, thereby improving performance. This also has the effect of reducing the energy required to make a particular journey.

Keywords: optimal driving strategy, high speed railway; train signalling system, brute force, genetic algorithm, active set.
\end{abstract}

\section{Introduction}

Many signalling systems have been developed since the first use of railways to improve strategies for safe train movement, from early fixed block signalling systems to moving block and, more recently, relative braking systems [1]. Each system has its own advantages and disadvantages in terms of investment cost, efficiency and stability. Therefore, before upgrading or building a railway line, it 
is important to select a signalling system that is able to meet the requirements of that line. The use of computer simulations can assist in selecting the correct signalling system in a simple and economic way. A number of researchers have investigated the use of train movement simulators to analyse railway signalling systems [2-4].

Once a signalling systems has been decided upon, to improve performance the train trajectory can be optimised. This is a complex problem, which can be undertaken by searching for the optimal train coasting points using methods such as genetic algorithms (GA) [5,6]. Other advanced methods such as artificial neural networks and fuzzy logic have also been employed to improve the efficiency and results of the optimisation $[7,8]$.

This paper describes the development and application of a computer simulator which is able to evaluate the performance of different signalling systems, including differences in journey time and train energy consumption. Using a multi-train simulator, five different signalling systems are simulated on a common section of high-speed line operating with two trains.

\section{Simulation case studies}

The multi-train simulator used in this paper was developed in MATLAB. It is able to simulate multiple train movements with differing signalling systems, traction performance and permitted speeds.

The simulated scenarios used in this paper include two high speed trains, which operate along a single track with three stations and a fixed station dwell time. When the simulation is complete, the simulator outputs journey time cost against distance, energy cost against distance and speed against distance relationships.

In this paper three main case studies are considered:

(1). Case Study 1 considers the operation of two trains, using a 4-aspect signalling system, with a headway that does not cause interactions between trains. This case study is used as a base case.

(2). Case Study 2 considers the effect of reducing the service interval to $200 \mathrm{~s}$. Five signalling systems are simulated.

(3). Case Study 3 considers how the train control strategy can be improved to optimise trajectories. A comparison is made between five signalling systems.

\subsection{Case Study 1 - undisturbed motion simulation}

The results of case study 1 , which considers two trains operating using a 4-aspect signalling system with a service interval of $285 \mathrm{~s}$ between trains, are shown in Figure 1. Each vertical marker on the $\mathrm{X}$-axis represents a signalling block. The letters 'G' (green), 'Y' (single-yellow), 'YY' (double-yellow), 'R' (red) in the figure indicate the signal aspect at a certain time. There are three stopping stations along the route, located at $0 \mathrm{~km}, 12.5 \mathrm{~km}$ and $27.5 \mathrm{~km}$. 


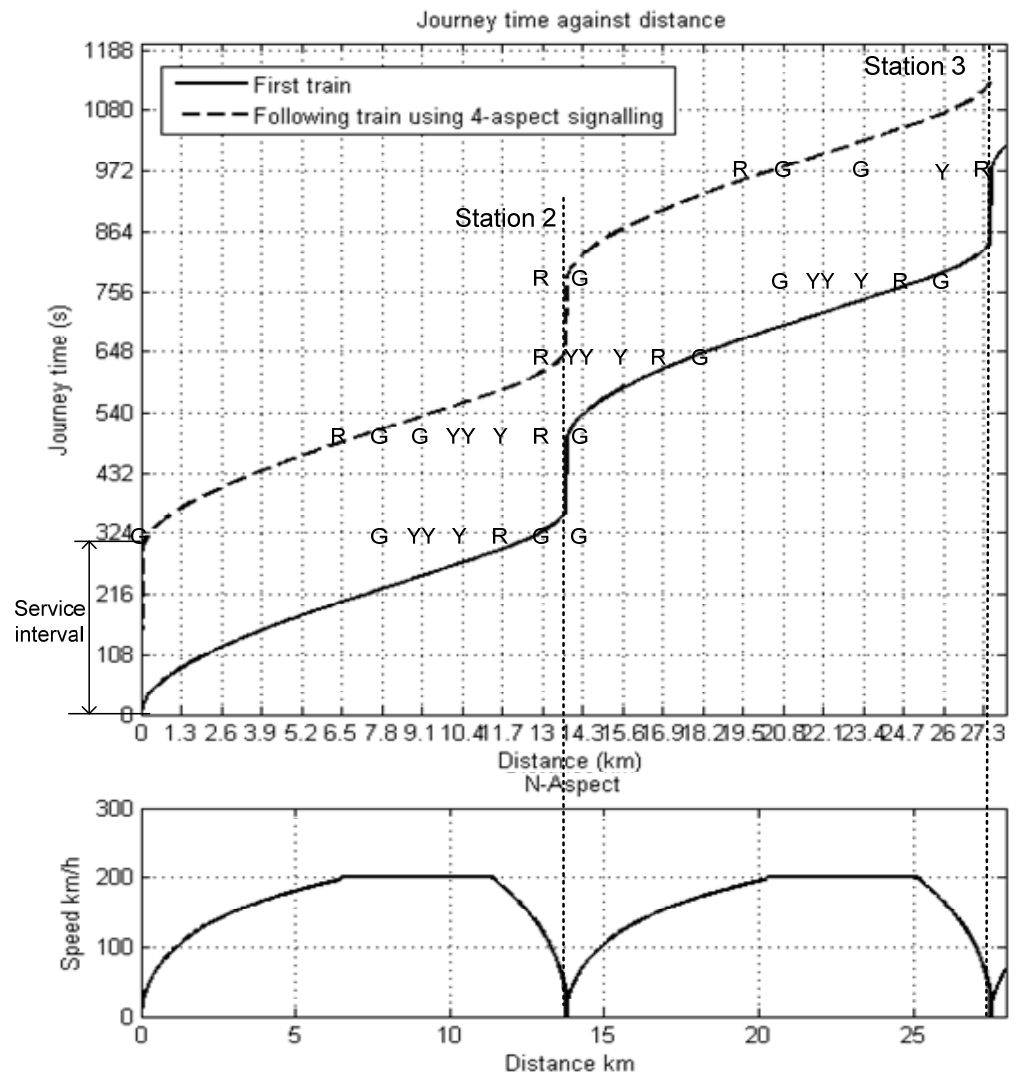

Figure 1: An undisturbed motion.

From the graph, it can be seen that there is no interaction between the trains during their journeys. The minimum service interval which results in an undisturbed motion is called the minimum line headway. The minimum line headway time includes train cruising time, braking time, dwell time and time for the train to clear the overlap and train length [9].

\subsection{Case Study 2 - disturbed motion simulations}

If the service interval is below the minimum line headway time, train interactions will occur. The scenario shown in Figure 2 shows a disturbed motion with a $200 \mathrm{~s}$ service interval. Interactions occur when the second train approaches each station.

The journey of the second train, as shown in Figure 1, can be described as follows:

(1). At point (a), the driver sees a double yellow signal when approaching the 9 th block. The train then starts to brake. 
(2). At point (b), the driver sees a single yellow signal when approaching the 10th block. The train therefore continues braking and prepares to stop before the next red signal.

(3). At point (c), the driver sees a single yellow signal again when approaching the 11th block. The train does not need to stop but should continue cruising at a low speed.

(4). At point (d), the train stops at the second station.

In this scenario, when the first train dwells at the second station, the distance interval between it and the following train is reduced. The journey of the second train will be disturbed as the distance between the two trains tends towards the minimum line headway distance. If the dwell time is extended for any reason, a more significant interaction will result between the two trains.

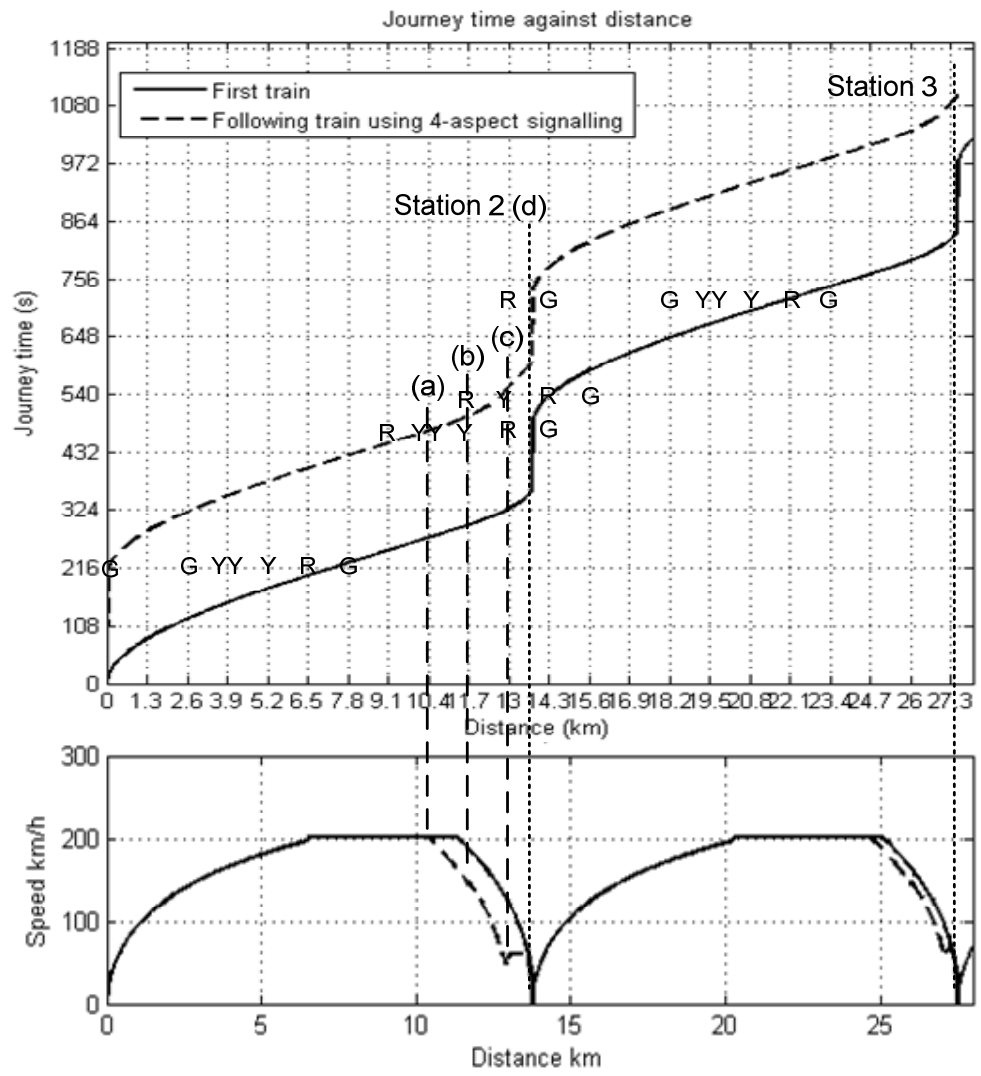

Figure 2: $\quad$ A disturbed motion.

Figure 3 shows the results of the same scenario when different signalling systems are used. 


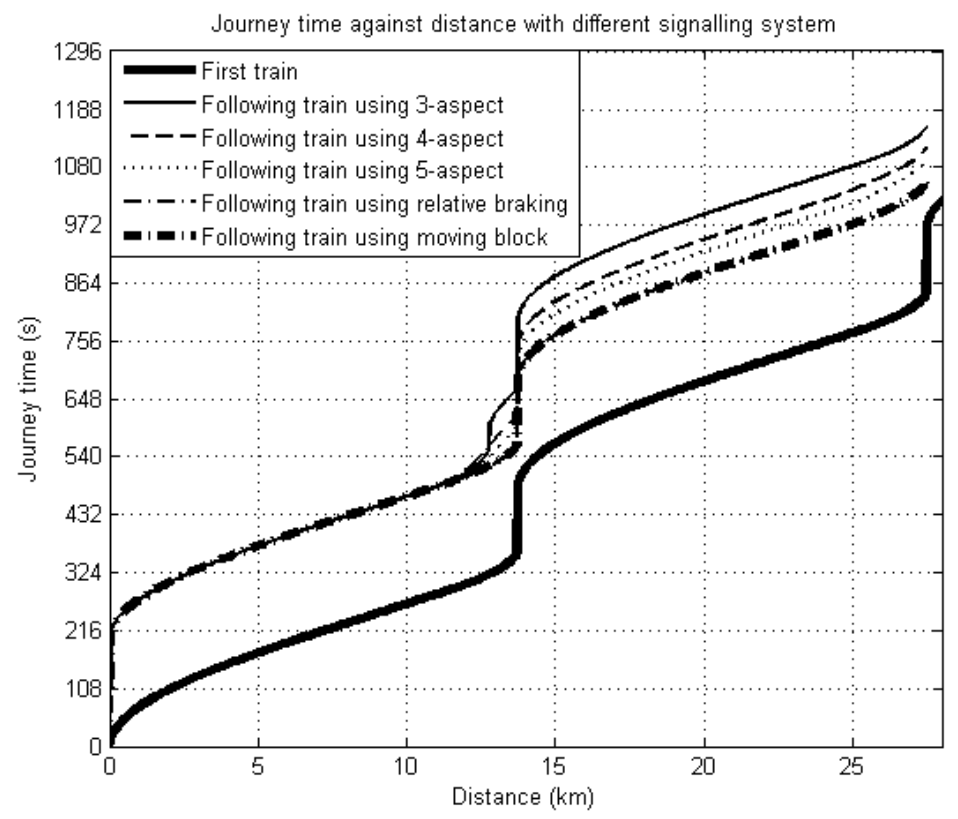

Figure 3: Journey time against distance for different signalling systems.

Several interesting performance characteristics can be observed:

(1). For fixed block signalling systems, performance improvement increases as more aspects are used. In this particular case study, there is a significant difference between 3-aspect and 4-aspect signalling systems; the second train comes to a complete stop when 3 -aspect signalling is applied.

(2). More advanced signalling systems provide better speed control strategies, resulting in fewer disturbances compared with simpler systems. However, the difference in performance between the most advanced signalling systems is small.

\subsection{Case study 3 - train speed limit levels optimisation}

\subsubsection{Introduction}

Changes in train velocity caused by train interactions increase energy consumption and reduce passenger comfort. Rather than requiring trains to run as quickly as possible, an optimal train control strategy which considers both journey time cost and energy cost could be the most appropriate for practical use.

The developed simulator can control the train trajectory through a series of train speed limit levels, as shown in the 'input' block in Figure 4. Using the simulator, the train journey time, and train energy usage can be calculated. In this case study, two speed limit levels are considered, three different operating 
priorities are defined and three search methods, namely Brute Force, Genetic Algorithm, and Active Set, are used to find the most appropriate speed limit levels to balance the minimum energy cost against the minimum journey time.

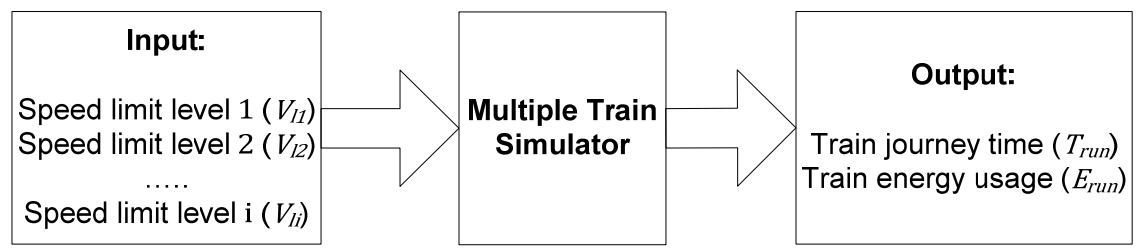

Figure 4: Flowchart of the train trajectory control.

The energy cost fitness function is shown as follows:

$$
\begin{gathered}
\text { fitness value }=E_{\text {run }} \times w_{e}+T_{\text {run }} \times w_{t} \\
E_{\text {run }}=f\left(V_{l 1} ; V_{l 2} ; a_{a c} ; a_{b r}\right), T_{\text {run }}=g\left(V_{l 1} ; V_{l 2} ; a_{a c} ; a_{b r}\right)
\end{gathered}
$$

where $E_{r u n}$ is the calculated energy cost; $T_{r u n}$ is the calculated journey time cost; $w_{e}$ and $w_{t}$ are the weightings associated with $E_{r u n}$ and $T_{r u n}$. Different conditions can be achieved by using different weighting sets. $V_{l l}$ is the train speed limit for the first part of the journey; $V_{12}$ is the train speed limit for the second part of the journey; $a_{a c}$ is the acceleration rate; $a_{b r}$ is the braking rate.

\subsubsection{Brute Force}

Brute Force initially enumerates all possible candidate solutions and outputs their journey time / energy cost pair. The lowest speed considered is $15 \mathrm{~ms}^{-1}$, and the highest limit is $55.6 \mathrm{~ms}^{-1}$ (the top speed of the train). Using a speed limit level search interval of $0.2 \mathrm{~ms}^{-1}, 41,616$ solution pairs are found. The pair with the same journey time and the lowest energy cost is identified. The journey time is incremented from $850 \mathrm{~s}$ to $1000 \mathrm{~s}$ with an interval of $0.5 \mathrm{~s}$, thus reducing the solution pairs to 301 . The results can be used to create a relationship between energy cost and journey time.

\subsubsection{Genetic Algorithm}

An alternative approach is to use a Genetic Algorithm (GA), an evolutionary algorithm that searches the solution space [10].

Each train speed limit level series is considered as one chromosome. Firstly, 20 chromosomes are chosen to create the first generation. Secondly, all chromosomes are evaluated by the train simulator and their journey time / energy cost pairs are ranked using the fitness function, eqn (1). Finally, in order to build 
up the next generation, 20 new chromosomes are created using the following processes:

(1). The top two ranking chromosomes are retained for the next generation.

(2). The next 14 ranked chromosomes are put into pairs and 'crossed-over', where each chromosome in a pair randomly swaps one of its genomes with its partner, thus creating two new chromosomes.

(3). The last four ranked chromosomes are mutated. Four new chromosomes are created by substituting one genome in each chromosome for a random value.

Using the new generation, the program then returns back to the second step and repeats the processes. This loop will continue until a termination condition has been achieved. In this case, 30 generations is set as the termination condition.

\subsubsection{Active Set}

A subset of inequalities can be calculated by using the estimation of the Active Set [11]. It aims to find the minimum of a constrained nonlinear multivariable function. In this case the cost function, eqn (1) is used.

The Active Set algorithm processes with the following steps:

(1). A search start point is given.

(2). The solution to the equality problem and its Lagrange multiplier are calculated.

(3). If the function tolerance is less than the set value, the optimisation will be stopped. If it is not, the program will remove a subset of the constraints by using the negative Lagrange multiplier.

(4). The program will calculate a new start point and constraint, then repeat this process from Step 2.

\subsubsection{Comparison of the searching methods}

Table 1 shows a comparison of the three different search methods. It can be seen that the average computational time of the Brute Force approach is much greater than the other methods. This is because the Brute Force algorithm calculates a journey time / energy cost pair for every speed limit search interval. The average computation time for the Brute Force approach could be reduced if the search interval is increased.

The Brute Force algorithm will always produce the optimum results. However, due to its large computation time, it is not practical for use in real-time applications. Nonetheless, the results produced can be used as reference values to compare the results from other search methods, as illustrated in Figure 2. In Figure 3 it can be seen that the Active Set algorithm is able to provide results close to the optimal values produced by the Brute Force algorithm; additionally, as shown in Table 2, the computation time is low. The Active Set algorithm is therefore used for further simulations in this paper. 
Table 1: Characteristic comparisons between three searching methods with journey time cost requirement of $900 \mathrm{~s}$ for 10 runs, Computer specifications: $\quad$ CPU $=$ Intel $\quad$ Core2 $\quad$ Q9550 $\quad(2.83 \quad \mathrm{GHz})$; Memory $=3 \mathrm{~GB}$; Operation system=Microsoft XP Professional SP3; MATLAB Version=7.11.0 (R2011b).

\begin{tabular}{|c|c|}
\hline Searching methods & Average computational time (s) \\
\hline Brute Force & $4,367.76$ \\
\hline Genetic Algorithm & 394.38 \\
\hline Active Set & 233.17 \\
\hline
\end{tabular}

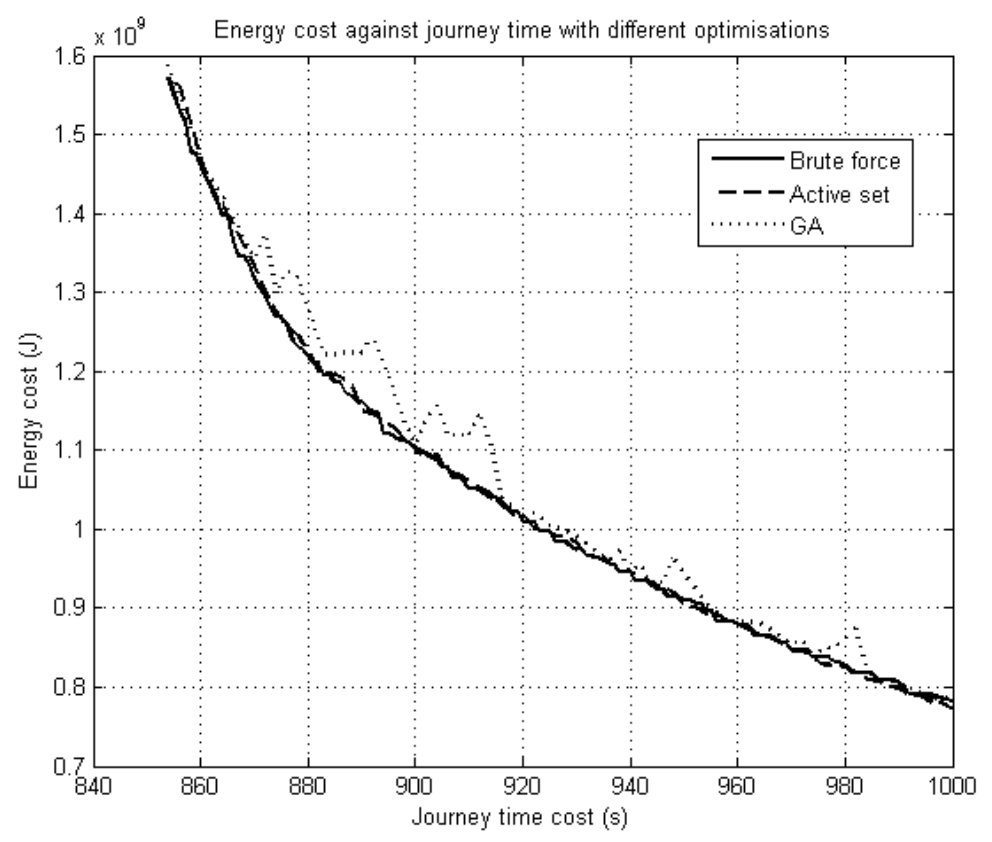

Figure 5: Journey time vs. energy cost curves using different searching methods.

\section{Results}

The simulations carried out in the previous sections show that, in general, faster journeys require more energy. In order to consider the trade-off between journey time and energy usage, three train control strategies are considered:

(1). Line speed running (flat-out): Trains always run at the maximum line speed, hence there is a significant likelihood of interactions between trains. Such interactions will result in increased journey times and energy costs. 
(2). Optimal journey time running (optimal): The train trajectory of the second train is optimised with respect to journey time, taking into account the interactions between the two trains. This will result in an optimal journey time at a moderate energy cost.

(3). Interactions avoidance running (cautious): A speed trajectory for the second train is calculated to ensure that no interactions occur between the two trains. This will result in a longer journey time with a lower energy cost.

Table 2: Journey time and energy cost against different train control strategies.

\begin{tabular}{|c|c|c|c|c|c|c|c|}
\hline & \multicolumn{2}{|c|}{$\begin{array}{c}\text { Train } 1 \text { - Non- } \\
\text { stop } \\
\text { Train } 2- \\
\text { Stopping } \\
\text { (no interaction) }\end{array}$} & \multicolumn{2}{|c|}{$\begin{array}{l}\text { Train 1 - Stopping } \\
\text { Train } 2 \text { - Stopping } \\
\text { (moderate } \\
\text { interaction) }\end{array}$} & \multicolumn{2}{|c|}{$\begin{array}{c}\text { Train } 1-\text { Stopping } \\
\text { Train } 2-\text { Non-stop } \\
\text { (significant interaction) }\end{array}$} \\
\hline & & $\begin{array}{c}\text { Journey } \\
\text { time } \\
\text { cost (s) }\end{array}$ & $\begin{array}{c}\text { Energy } \\
\text { cost } \\
(\mathrm{kWh}) \\
\end{array}$ & $\begin{array}{l}\text { Journey } \\
\text { time } \\
\text { cost (s) }\end{array}$ & $\begin{array}{l}\text { Energy } \\
\text { cost } \\
(\mathrm{kWh}) \\
\end{array}$ & $\begin{array}{c}\text { Journey } \\
\text { time cost } \\
(\mathrm{s}) \\
\end{array}$ & $\begin{array}{c}\text { Energy cost } \\
(\mathrm{kWh})\end{array}$ \\
\hline \multirow[t]{3}{*}{$\begin{array}{c}\text { 3-aspect } \\
\text { signalling }\end{array}$} & $\begin{array}{l}\text { Flat-out } \\
\text { running }\end{array}$ & 846 & 429 & 969 & 439 & 988 & 426 \\
\hline & $\begin{array}{l}\text { Optimal } \\
\text { running }\end{array}$ & 846 & 429 & $\begin{array}{c}955 \\
(-1 \%)\end{array}$ & $\begin{array}{c}378 \\
(-14 \%)\end{array}$ & $\begin{array}{c}973 \\
(-2 \%)\end{array}$ & $\begin{array}{c}183 \\
(-57 \%)\end{array}$ \\
\hline & $\begin{array}{c}\text { Cautious } \\
\text { running }\end{array}$ & 846 & 429 & $\begin{array}{l}1001 \\
(3 \%)\end{array}$ & $\begin{array}{c}289 \\
(-34 \%)\end{array}$ & $\begin{array}{c}985 \\
(-0.3 \%)\end{array}$ & $\begin{array}{c}126 \\
(-70 \%)\end{array}$ \\
\hline \multirow[t]{3}{*}{$\begin{array}{c}\text { 4-aspect } \\
\text { signalling }\end{array}$} & $\begin{array}{l}\text { Flat-out } \\
\text { running }\end{array}$ & 846 & 429 & 920 & 446 & 913 & 437 \\
\hline & $\begin{array}{l}\text { Optimal } \\
\text { running }\end{array}$ & 846 & 429 & $\begin{array}{c}911 \\
(-1 \%) \\
\end{array}$ & $\begin{array}{c}368 \\
(-17 \%) \\
\end{array}$ & $\begin{array}{c}896 \\
(-2 \%) \\
\end{array}$ & $\begin{array}{c}166 \\
(-62 \%) \\
\end{array}$ \\
\hline & $\begin{array}{c}\text { Cautious } \\
\text { running }\end{array}$ & 846 & 429 & $\begin{array}{c}938 \\
(2 \%) \\
\end{array}$ & $\begin{array}{c}279 \\
(-37 \%)\end{array}$ & $\begin{array}{c}914 \\
(0.1 \%)\end{array}$ & $\begin{array}{c}126 \\
(-71 \%) \\
\end{array}$ \\
\hline \multirow[t]{3}{*}{$\begin{array}{c}\text { 5-aspect } \\
\text { signalling }\end{array}$} & $\begin{array}{l}\text { Flat-out } \\
\text { running }\end{array}$ & 846 & 429 & 892 & 436 & 888 & 431 \\
\hline & $\begin{array}{l}\text { Optimal } \\
\text { running }\end{array}$ & 846 & 429 & $\begin{array}{c}891 \\
(-0.1 \%) \\
\end{array}$ & $\begin{array}{c}415 \\
(-5 \%) \\
\end{array}$ & $\begin{array}{c}870 \\
(-2 \%) \\
\end{array}$ & $\begin{array}{c}154 \\
(-64 \%) \\
\end{array}$ \\
\hline & $\begin{array}{c}\text { Cautious } \\
\text { running }\end{array}$ & 846 & 429 & $\begin{array}{c}946 \\
(6 \%) \\
\end{array}$ & $\begin{array}{c}264 \\
(-39 \%)\end{array}$ & $\begin{array}{c}890 \\
(0.2 \%)\end{array}$ & $\begin{array}{c}130 \\
(-70 \%) \\
\end{array}$ \\
\hline \multirow[t]{3}{*}{$\begin{array}{c}\text { Moving } \\
\text { block }\end{array}$} & $\begin{array}{l}\text { Flat-out } \\
\text { running }\end{array}$ & 846 & 429 & 849 & 441 & 831 & 423 \\
\hline & $\begin{array}{l}\text { Optimal } \\
\text { running }\end{array}$ & 846 & 429 & $\begin{array}{c}849 \\
(0 \%)\end{array}$ & $\begin{array}{c}441 \\
(0 \%)\end{array}$ & $\begin{array}{c}821 \\
(-0.1 \%)\end{array}$ & $\begin{array}{c}206 \\
(-51 \%)\end{array}$ \\
\hline & $\begin{array}{c}\text { Cautious } \\
\text { running }\end{array}$ & 846 & 429 & $\begin{array}{c}891 \\
(5 \%) \\
\end{array}$ & $\begin{array}{c}325 \\
(-26 \%) \\
\end{array}$ & $\begin{array}{c}853 \\
(3 \%) \\
\end{array}$ & $\begin{array}{c}132 \\
(-69 \%) \\
\end{array}$ \\
\hline \multirow[t]{3}{*}{$\begin{array}{l}\text { Relative } \\
\text { braking }\end{array}$} & $\begin{array}{l}\text { Flat-out } \\
\text { running }\end{array}$ & 846 & 429 & 855 & 439 & 829 & 398 \\
\hline & $\begin{array}{l}\text { Optimal } \\
\text { running }\end{array}$ & 846 & 429 & $\begin{array}{c}854 \\
(-0.1 \%) \\
\end{array}$ & $\begin{array}{c}411 \\
(-6 \%)\end{array}$ & $\begin{array}{c}815 \\
(-2 \%)\end{array}$ & $\begin{array}{c}189 \\
(-52 \%)\end{array}$ \\
\hline & $\begin{array}{c}\text { Cautious } \\
\text { running }\end{array}$ & 846 & 429 & $\begin{array}{c}870 \\
(2 \%) \\
\end{array}$ & $\begin{array}{c}358 \\
(-18 \%) \\
\end{array}$ & $\begin{array}{c}848 \\
(2 \%) \\
\end{array}$ & $\begin{array}{c}133 \\
(-66 \%) \\
\end{array}$ \\
\hline
\end{tabular}

Table 2 shows the journey times and energy costs for three scenarios with different combinations of stopping and non-stop services (the numbers in 
brackets show the percentage difference compared with line speed running). Five different signalling systems are considered with each of the three different train control strategies.

It can be seen in Table 2 that significant differences in journey time and energy cost are experienced when interactions occur between trains. For example, for fixed block signalling systems, an energy reduction of up to $64 \%$ can be achieved if train interactions are eliminated by changing from Line Speed Running to Optimal Journey Time Running, which also provides a journey time reduction of almost $2 \%$. For moving block and relative systems the energy savings are not as large, but are still significant.

When switching from Line Speed Running to Interaction Avoidance Running, journey times are increased slightly, but energy costs are decreased significantly. Energy savings can be reduced by as much as $71 \%$ for an increase in journey time of $0.1 \%$.

\section{Conclusions}

This paper has analysed the differences in journey time and energy usage on a high-speed line when different signalling systems and train control strategies are employed.

Brute Force, Genetic Algorithm and Active Set searching methods were compared for calculating optimal trajectories. The Active Set method was shown to provide close to optimal results with a low computational time, and it was therefore concluded that this method was well suited to solve such problems. It was found that by applying optimal train control strategies it is possible to reduce the number of interactions and reduce energy usage.

\section{References}

[1] Tetsuo T., Signalling systems for safe railway transport. Japan railway \& Transport review, 1999.

[2] Chang C.S., Chua C.S., Quek H.B., Xu X.Y. and Ho S.L., Development of train movement simulator for analysis and optimisation of railway signalling systems. International conference on Developments in Mass Transit Systems, 1998(Conf Publ No 453), pp. 243-248, 1998.

[3] Liu H., Mao B., Ho T., Ding Y. and Wang X., Study on tracking operation between trains of different block modes and simulation system. China Railway Science, 27(2), pp. 120-126, 2005.

[4] Hill R.J. and Bond L.J., Modelling moving-block railway signalling systems using discrete-event simulation. Railroad Conference, 1995, Proceedings of the 1995 IEEE/ASME Joint, pp. 105-111, 1995.

[5] Bocharnikov Y.V., Tobias A.M., Roberts C., Hillmansen S. and Goodman C., Optimal driving strategy for traction energy saving on DC suburban railways. Electric Power Applications, IET, 1(5), pp. 675-682, 2007. 
[6] Chang C.S. and Sim S.S., Optimising train movements through coast control using genetic algorithms. Electric Power Applications, IEE Proceedings, 144(1), pp. 65-73, 1997.

[7] Acikbas S. and Soylemez M.T., Coasting point optimisation for mass rail transit lines using artificial neural networks and genetic algorithms. Electric Power Applications, IET, 2(3), pp. 172-182, 2008.

[8] Hee-Soo H., Control strategy for optimal compromise between trip time and energy consumption in a high-speed railway. Systems, Man and Cybernetics, Part A: Systems and Humans, IEEE Transactions on, 28(6), pp. 791-802, 1998.

[9] Woodland D., Optimisation of automatic train protection systems. Department of Mechanical Engineering, University of Sheffield, 2004.

[10] Cox E., Fuzzy modelling and genetic algorithms for data mining and exploration, Morgan Kaufmann, 2005.

[11] Judice J., Vicente L.N. and Portugal L.F., A comparison of block pivoting and interior point algorithms for linear least squares problems with nonnegative variables. Mathematics of Computation, 63(208), pp. 625-643, 1994. 